\title{
AN APPLICATION TO SUPPORT FIELD TECHNICIANS IN THE MAINTENANCE OF WI-FI HOTSPOTS IN THE TOWNSHIP OF MAKHANDA
}

\author{
Gibson Munene Muriithi, Nomusa Dlodlo and Alfredo Terzoli \\ Rhodes University, Drodsty Street, Grahamstown, South Africa
}

\begin{abstract}
Today, the internet is an essential part of people's lives as it is used every day in communication, education, business, and government-related services. Therefore, there is a need to ensure that internet connectivity is stable to help people, businesses, and schools achieve their optimum productivity. A local wireless service provider (WISP) called Khula Tech is about to start the roll-out of some WiFi hotspots in the township of Makhanda in South Africa. To ensure a satisfactory up-keep of the hotspots, and given a limited workforce with a limited skill set, a mobile application called Khula Tech Network Management System (KTNMS) was developed in this research to help the technicians working in the field. The application will be integrated into the WISP back-end systems of Splynx and Ubiquiti Network management (UNMS) to automate the back-end operations as much as possible. Splynx is an inventory management system. UNMS monitors the network for any breakdowns. The application is a cross-platform mobile application that is supported on Android and iOS devices.
\end{abstract}

\section{KEYWORDS}

Cross-Platform, APIs, Mobile Application, WiFi

\section{INTRODUCTION}

With limited connections and access to the internet, peri-urban and rural areas may not be able to fully access the vast information on the internet that could significantly improve their businesses, studies, research, and livelihoods. Thus, the internet could play a tremendously positive role in reducing poverty, moreso in the peri-urban and rural areas (Kenny 2000). Most studies show that there is a positive correlation between access to telecommunication capabilities and improvements in specific economic indicators (Parker \& Hudson 1992). Access to a reliable internet connection across South Africa will ensure that the public is well informed. This may, in turn, also raise the reading proficiency and knowledge levels of the citizens, as there is much study material available on the internet. The internet has become a necessity for learning, entertainment, socializing, and for businesses. It has encouraged businesses, schools, universities, and the government to come up with ways to ensure that everyone has access to the internet, and that is through setting up WiFi hotspots. A WiFi hotspot is a physical point where internet connectivity is available through WiFi via a wireless network with a router connected to an internet service provider (ISP). In South Africa, the number of internet users is increasing fast, compared to other developing countries. Research about internet connection in South Africa conducted by Statista in 2019 showed that 63.8 percent of the South African population had access to the internet. It is projected that this share might grow to 80.8 percent by 2023 (Clement 2019). This rapid growth of internet use leaves some populations and areas like the townships behind due to the costs. The word "township" in South Africa refers to a non-white neighborhood, a term borrowed from apartheid South Africa (Ju ̈̈gens et al. 2013). The South African townships are characterized by rudimentary infrastructure, resulting in low public services, recreational facilities, industry, transport, and green spaces. Townships in South Africa have always been marginalized. One of the areas of marginalization is in access to telecommunications services, including broadband access. As a result, the South African government has come up with a national broadband policy and an associated strategy called SA Connect, which is meant to deliver broadband access. Due to this, the government and some businesses are making an initiative to install WiFi hotspots to make the internet more affordable and accessible to people in these areas since the user doesn't have to incur any capital equipment costs. Having a large number of WiFi hotspots makes it difficult for businesses to manage and monitor all the hotspots. The Makhanda Township WiFi hotspots project taps into the SA Connect strategy. 
A local Wireless Solutions Internet Service Provider (WISP) in Makhanda called Khula Tech is about to start the roll-out of several WiFi hotspots in the township of Makhanda. It is the only service provider with high connectivity points in that area, which will ensure that this process will be carried out quickly and effectively since they already have the connectivity towers set up. In Makhanda Township, the WiFi hotspots build a wireless canopy over the township to push home connectivity without needing a router in each home and can be used by nomadic users. This research develops an application that will support local field technicians in maintaining the WiFi hotspots in Makhanda Township. These technicians are semi-skilled and are not necessarily proficient in the English language. The application developed takes cognizance of such issues. There is thus a need to create an application that will help the field technicians to be able to maintain hotspots.

\section{PROBLEM STATEMENT}

Internet connectivity in peri-urban areas is relatively low and not affordable since the communities rely heavily on mobile broadband, and the costs are relatively high (Government 2017). This prevents most people in these areas from accessing the internet since they cannot afford day to day data bundles. The local WISP, Khula Tech, has around 300 hotspots in the Makhanda Township, making it hard to pinpoint failures and breakdowns due to many hotspots. This results in the internet access being inefficient and resulting in customer dissatisfaction. Due to many hotspots, it is also hard to know which particular hotspot might be down since the current system only gives details of the internet protocol (IP) address and not the exact location. The company has a limited workforce with a limited skills set, leading to challenges in managing the hotspots. The challenges arise because the two systems of Splynx and Ubiquiti Network Management System (UNMS) that the company currently uses are complex. As such, interaction with them requires technical computer skills and hardware, which the technicians might not have. This is why there is a need to implement a mobile application that will help Khula Tech monitor the routers and get notifications in case of any issues or breakdowns

\section{AIM AND OBJECTIVES}

The aim of the research was to:

- Design and develop a mobile application to support field technicians in the management of WiFi hotspots using a platform that integrates Splynx and UNMS.

The objectives of the research are therefore, to:

- Design a simple and easy to use interface so as to enable the less skilled technician to understand and be able to use the application quickly without much guidance.

- Enable interaction with the Splynx system to get information about the company's inventory.

- Enable the creation of tickets with the company's Splynx system so as to make communication with the company easy and fast since the technicians will be able to report any issues they face while in the field.

- Enable viewing of allocated tickets and tasks of the technicians

- Enable the UNMS to obtain the network statistics, notifications and site details.

\section{APPROACH}

Before embarking on this research, understanding the programming in the platform to be used and how it can interact with the backend systems Splynx and UNMS was necessary. An incremental approach was followed in the development of the application, and this was typically supported by a series of incrementally improved prototypes until a satisfactory mature-enough product was reached. Following this approach, the system was designed, implemented, and tested incrementally until the product was complete.

The application is able to communicate with the two systems that the company is currently using, that is, Splynx and UNMS. The application communicates with these two systems through Application Program Interfaces (APIs). As such, the need to understand how each system's API works and how to implement the APIs in the application. UNMS always reports if an access point is down, and as a result, these breakdowns 
had to be picked up via the APIs. Splynx is a customer relationship management system (CRMS), and in this case, manages the company's inventory. The following processes were followed in this research:

- Undertake requirements specifications for the mobile application through assessing the functionalities provided by the Splynx and UNMS.

- Design the mobile application.

- Implement the mobile application.

- $\quad$ Testing the mobile application.

\section{RELATED SYSTEMS}

The following are systems that are closely-related to the mobile application that was developed in this research.

- Project Isizwe (Xala 2018) that connects low-income initiatives across South Africa for social inclusion. The project deploys free public internet WiFi hotspots within walking distance in low-income communities for educational, economic, and social inclusion in order to address inequality.

- WiFi Tshwane project (Xala 2018) has 780 hotspots. It connects residents in the City of Tshwane from libraries, clinics, swimming pools, schools, and bus stations in order to empower its communities through connectivity. Smart spaces are created to form a smart connected city.

- Airports Company SA (Xala 2018) provides free WiFi services for passengers in boarding areas in 6 international airports

- Jozi Digital Ambassadors (Xala 2018) has hotspots in Johannesburg's libraries, clinics, Rea Vaya bus stations, and government buildings. The project is a cooperation between the City of Johannesburg and the University of Johannesburg that offers residents the opportunity to access wireless facilities around the city through young digital educators.

- City Bowl Natives (Xala 2018) in Cape Town connects clinics, administration buildings, traffic departments, and cash offices.

- Mobile hotspots exist in Port Elizabeth (Xala 2018) where residents in under-resourced areas are allocated 100MB daily.

- From 2019, through a project funded by Google (de Villiers 2019), residents in the Cape Flats have unlimited free WiFi. WiFi access is enabled through WiFi Towers of Google stations for inclusive participation in the global economy. Cell C will partner with Google to use lamp posts, bus stops, transport hubs, and council-owned buildings as WiFi hotspots.

- VAST (WAKAMA 2017) was a leading open-access WiFi provider in Gauteng that was set to give 15 million township residents an affordable alternative to access the internet. They sold $1.5 \mathrm{~GB}$ of WiFi vouchers for a nominal fee of R50 through retail outlets and entrepreneurial vendors (Prior 2018). The failure of VAST came about because the implementation costs and the on-going service provision costs were quite high (Mzekandaba 2019). The returns based on advertising and registration were very low as compared to these costs.

\section{RESULTS}

The main result of the research work reported in this paper is the prototype of an application to support the fieldwork of the technicians who maintain the hotspots. So, this section presents a walk-through of the prototype built through the listing of screengrabs obtained during the execution of the built application. The walk-through is done on an Android device.

\subsection{User Interfaces}

The Splash screen is the first screen that opens when the application is launched, and the user is not yet logged in. It contains the Khula Tech logo and a navigation option to log in (see Figure 1(a)).

The Sign-in screens for Splynx (see Figure 1(b)) and UNMS are the screens where a user inputs their credentials in order to access most features of the application. Each screen contains a text-field for the username and password and a button for login. The user has the option to reveal and check the password input. Also, if 
the user inputs a password or username shorter than the required size, then there is an error box under the text field. There are two servers to be used in the application, hence the need for two login forms. The data inputs are validated before proceeding to the next screens. The login starts with the Splynx login, and then if data is correct, the user is redirected to the UNMS login.

The Home screen (see Figure 2(a)) is the screen the user is redirected to after they are logged in with the UNMS server. It consists of network statistics like network stability, outages, live sites, inactive sites, and many more. The side drawer can be accessed from this screen. The drawer is located at the top left corner of the screen.

The Notification screen (see Figure 2(b)) is where a user is able to view all net- work notifications. The Notification screen has three top navigation tabs: the error, warning, and information tabs. This is because there are three categories of notifications in the mobile application. Each notification has a color icon to symbolize the type of notification. Red means that there is an error or outage, and orange shows a warning.

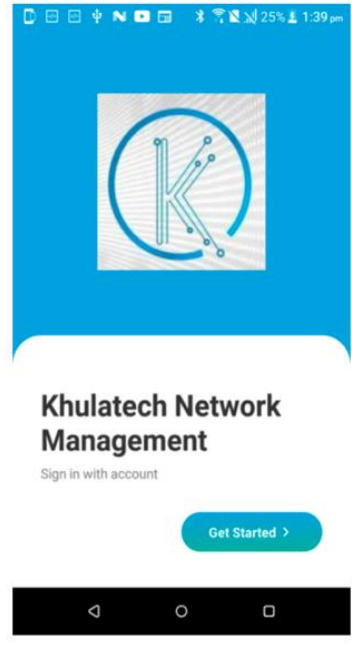

(a) Splash screen

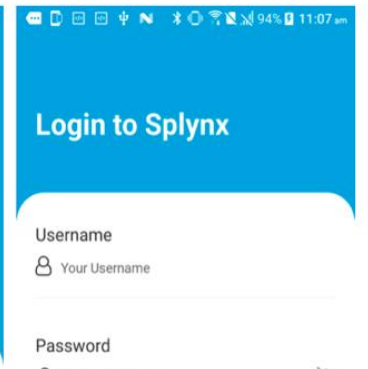

B Your Password Sign In

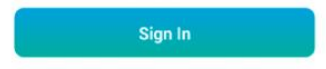

$\triangleleft$

(b) Splynx login screen

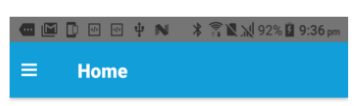

$94 \%$
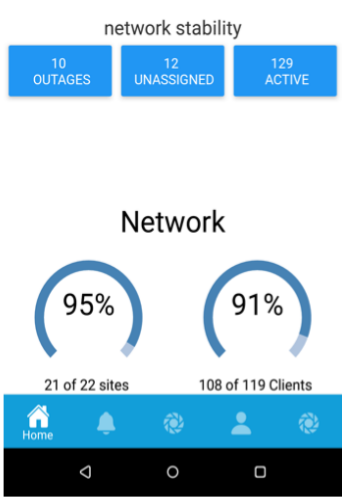

(a) Home screen

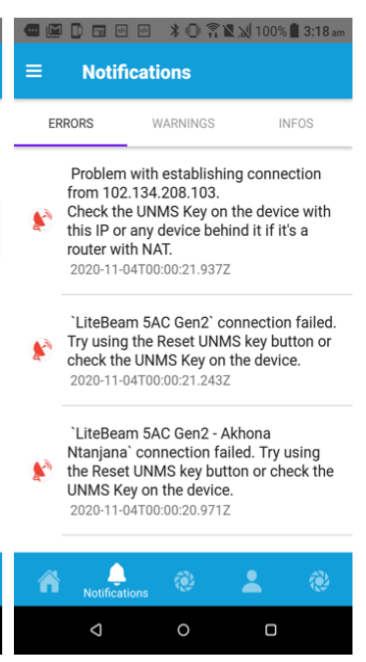

(b) Notification error screen

Figure 1. Splash and sign in screens

The Sites screen (see Figure 3(a)) is where a user is able to view all site information. This screen has three top navigation tabs, namely, Sites, Disconnected, and Inactive, and this is because there is an option to view all sites and to view all disconnected and inactive sites. There is a color icon showing the status of the sites. Red means disconnected, green means active, and grey means inactive. The disconnected tab shows all the disconnected sites, clients, and endpoints. The inactive sites screen is to display all the inactive sites, clients, and endpoints.

The Ticket screen (see Figure 3(b)) shows a list of all tickets allocated to the technicians by the administrator. The technicians are able to view these tickets and also update their status. There are some sections of the screen that are hidden because they contain real customer names.

The Inventory screen (see Figure 4(a)) shows the company's inventory and also the available quantity and the sell prices. In the future, the technicians will be able to make a request for an order of an inventory.

The Drawer screen (see Figure 4(b)) is a user interface panel that displays the application's navigation menu. By default, it will be hidden when not in use but will appear when the user swipes a finger from the edge of the screen or when the user touches the top-drawer icon added to the application bar. will be available on all the application screens. 


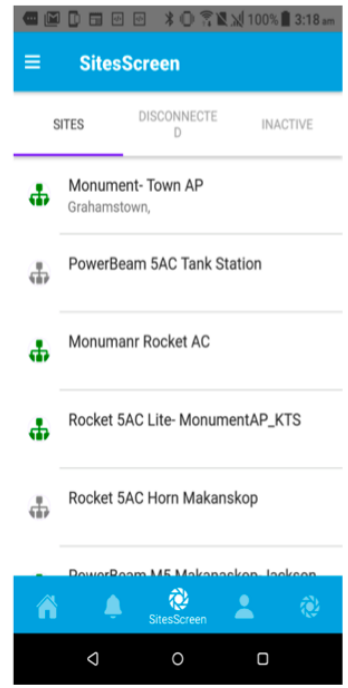

(a) Sites screen

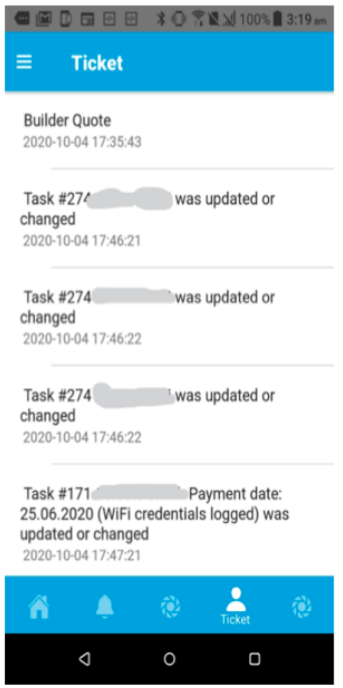

(b) tickets screen

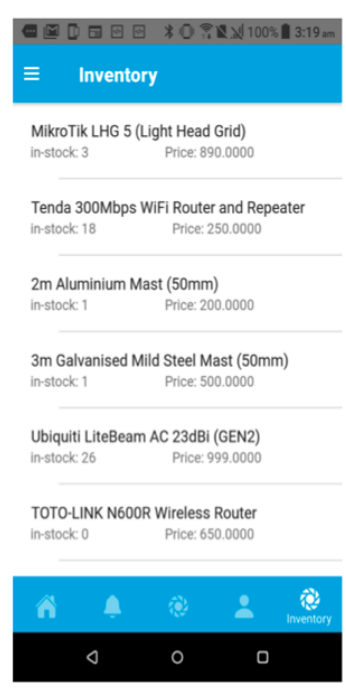

(a) Inventory screen

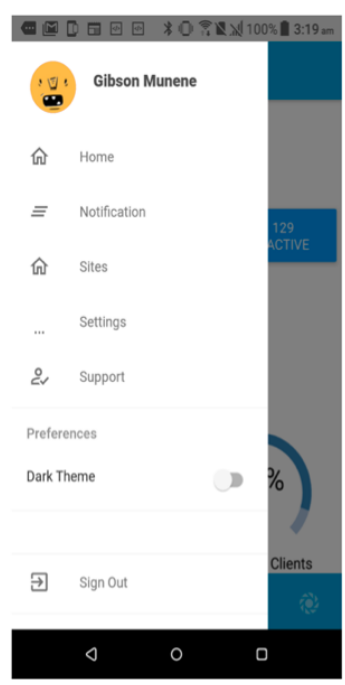

(b) Drawer screen

Figure 3. Sites and ticket screens

Figure 4. Inventory and drawer screens

\section{CONCLUSION}

The project was conducted with the aim of designing a network management mobile applications to assist a local WISP in their hotspots project in the township of Makhanda. This was done achieved by using a crossplatform development language called React Native. The mobile application has the potential to provide a good and reliable monitoring and maintenance system. The research is at prototype stage and field research on the application is yet to be conducted.

\section{REFERENCES}

Clement, J. (2019), 'Internet user penetration in south africa from 2017 to 2023', Demographic \& use. URL: https://www.statista.com/statistics/484933/internet-user-reach- south-africa/

de Villiers, J. (2019), 'Langa, khayelitsha and gugulethu residents can now get unlimited free wifi through google'. URL: https://www.htxt.co.za/2018/09/11/the-current-state-of-free-public- wifi-in-south-africa/

Government, W. C. (2017), 'Switching on public wi-fi hotspots across the western cape'.

Ju rgens, U., Donaldson, R., Rule, S. \& B ähr, J. (2013), 'Townships in south african cities-literature review and research perspectives', Habitat International 39, 256-260.

Kenny, C. J. (2000), 'Expanding internet access to the rural poor in africa', Information Technology for Development 9(1), $25-31$.

Lerum, C. B., Nelson, J. A. \& de Matos Capistrano, A. (2014), 'Integrated application localization'. US Patent 8,789,015.

Mzekandaba, S. (2019), 'Vast falls to challenges of monetising public wifi'. URL: https://www.itweb.co.za/content/mYZRXv9PjYWqOgA8

Parker, E. B. \& Hudson, H. E. (1992), 'Electronic byways: State policies for rural development through telecommunications'.

Prior, B. (2018), 'Vast networks launches $1.5 \mathrm{gb}$ wi-fi vouchers for r50'. URL: https://mybroadband.co.za/news/internet/287212-vast-networks-launches-1-5gb-wi-fi-vouchers-for-r50.html

WAKAMA, A. (2017), 'South africa: Over 1 million township residents to get wifi'. URL: https://www.itnewsafrica.com/2017/04/south-africa-over-1-million-township-residents-to-get-wifi/

Xala, N. (2018), 'The current state of free public wifi in south africa'. URL: https://www.htxt.co.za/2018/09/11/the-currentstate-of-free-public- wifi-in-south-africa 